\title{
Failure of prophylactic intravenous immunoglobulin to prevent sensitization to cryopreserved allograft tissue used in congenital cardiac surgery
}

Steven R. Meyer, MD, PhD, ${ }^{a}$ David B. Ross, MD, ${ }^{\mathrm{a}, \mathrm{c}}$ Karen Forbes, MD, ${ }^{\mathrm{c}}$ Lois E. Hawkins, $\mathrm{RN}, \mathrm{MN}^{\mathrm{c}}{ }^{\mathrm{c}}$ Anne M. Halpin, MSc, ${ }^{\text {b }}$ Susan N. Nahirniak, MD, ${ }^{b}$ Jennifer M. Rutledge, MD, ${ }^{c}$ Ivan M. Rebeyka, MD, ${ }^{a, c}$ and Patricia M. Campbell, MBChB ${ }^{\mathrm{b}}$

From the Departments of Surgery a and Laboratory Medicine and Pathology, ${ }^{\mathrm{b}}$ University of Alberta, ${ }^{c}$ and the Department of Pediatrics, Stollery Children's Hospital, University of Alberta, Edmonton, Alberta, Canada.

Supported by the Stollery Children's Hospital Foundation.

Received for publication Oct 30, 2006; revisions received Dec 1, 2006; accepted for publication Dec 13, 2006.

Address for reprints: Steven R. Meyer, MD, PhD, 4B4.26 Walter Mackenzie HSC, 8440112 St, Edmonton, Alberta, T6G 2B7 Canada (E-mail: srmeyer@charter.net).

J Thorac Cardiovasc Surg 2007;133:1517-23 0022-5223/ $\$ 32.00$

Copyright $(9) 2007$ by The American Association for Thoracic Surgery

doi:10.1016/j.jtcvs.2006.12.019
Objective: Cryopreserved allograft tissue used in the Norwood procedure for infants with hypoplastic left heart syndrome causes profound immunologic sensitization, which may complicate future transplantation. Intravenous immunoglobulin has been shown to reduce sensitization after it has developed, allowing successful transplantation. The purpose of this pilot trial was to determine whether intravenous immunoglobulin given before and after the procedure could prevent sensitization to cryopreserved allograft patches used in the initial repair of hypoplastic left heart syndrome.

Methods: Intravenous immunoglobulin ( $2 \mathrm{~g} / \mathrm{kg}$ ) was given preoperatively, 3 weeks postoperatively, and 4 months postoperatively to 7 infants undergoing the Norwood procedure. Panel-reactive antibodies were measured with flow cytometry preoperatively and at 1, 4, 6, and 12 months postoperatively and compared with values from a contemporary cohort of 12 infants undergoing the Norwood procedure who did not receive intravenous immunoglobulin.

Results: The groups were well matched for length and weight at time of surgery. Control infants were somewhat younger than the cohort receiving intravenous immunoglobulin $(8 \pm 5$ vs $17 \pm 14$ days, $P=.021)$. There were no differences in transfusion requirements. There was no difference in the degree of sensitization between control and intravenous immunoglobulin groups at 1 month (class I panel-reactive antibodies $20 \% \pm 30 \%$ vs $4 \% \pm 9 \%, P=.443$, class II panelreactive antibodies $17 \% \pm 27 \%$ vs $20 \% \pm 17 \%, P=.400$ ), 4 months (class I panel-reactive antibodies $62 \% \pm 40 \%$ vs $73 \% \pm 41 \%, P=.813$, class II panelreactive antibodies $49 \% \pm 42 \%$ vs $54 \% \pm 41 \%, P=.706$ ), and 12 months (class I panel-reactive antibodies $49 \% \pm 42 \%$ vs $58 \% \pm 39 \%, P=.686$, class II panel-reactive antibodies $44 \% \pm 36 \%$ vs $49 \% \pm 42 \%, P=.651)$.

Conclusion: Despite studies showing intravenous immunoglobulin to reduce sensitization, we were unable to demonstrate that intravenous immunoglobulin prevented sensitization after exposure to allograft tissue in neonates undergoing congenital cardiac surgery.

I t has been well documented that previous sensitization complicates solid organ transplantation. In cardiac transplantation, the presence of preformed anti-HLA antibodies, measured as panel reactive antibody (PRA), is associated with earlier and more frequent high-grade rejection, ${ }^{1,2}$ increased graft vasculopathy, ${ }^{3}$ and decreased survival. ${ }^{4}$ Importantly, Jacobs and colleagues ${ }^{5}$ recently reported that in pediatric transplantation (median age 130 days), a PRA level greater than $10 \%$ was associated with increased 30-day (25\%) and long term (50\%) mortality relative to those with a PRA level less than $10 \%$ (8\% and 15\%, respectively). Moreover, 


\section{Abbreviations and Acronyms \\ HLHS = hypoplastic left heart syndrome \\ IVIG = intravenous immunoglobulin \\ PRA = panel-reactive antibody}

written consent was obtained from parents on behalf of the patients. This study was funded by the Stollery Children's Hospital Foundation at the University of Alberta. The funding agency played no role in designing the study; in collecting, analyzing, and interpreting the data; in writing the report; or in making the decision to submit for publication.

\section{Study Cohort}

Seven infants with HLHS undergoing first-stage palliation (Norwood procedure) with a cryopreserved allograft pulmonary artery patch were studied. Allograft tissue was provided by comprehensive tissue centers at two Canadian University Hospitals (University of Alberta Hospital, Edmonton, Alberta, Canada, and Sick Kids Hospital, Toronto, Ontario, Canada).

\section{Control Cohort}

Data from 12 infants with HLHS who had previously undergone the Norwood procedure with an allograft patch to reconstruct the aortic arch 12 to 18 months before this study were reviewed. These 12 infants had been included in a previously reported study, ${ }^{10}$ which had been approved by the local institutional review board. No significant changes had been made in operative or perioperative management during this short interval, and thus temporal bias is presumed to be limited.

\section{Intravenous Immunoglobulin}

IVIG 10\% (Gammunex, caprylate and chromatography purified, 2 $\mathrm{g} / \mathrm{kg}$ ) was administered 1 day preoperatively and 3 weeks and 4 months postoperatively. Because of the volume-sensitive physiology of these children, IVIG was administered during hospitalization: preoperative, 3 weeks postoperative, and at the time of the bidirectional cavopulmonary anastomosis procedure (4 months). The first 2 doses are consistent with the 3 -week half life of IVIG and previously described protocols ${ }^{15-18}$; the timing of the third dose obviated a separate readmission specifically for the study. IVIG was infused according to established guidelines and given over the course of at least 8 hours.

\section{Variables}

Preoperative variables to ensure similarity between the two groups included age, sex, length, and weight. Perioperative factors included durations of crossclamping and cardiopulmonary bypass, use of hypothermic circulatory arrest, and blood product exposure (amount and type).

\section{Donor and Recipient HLA Typing}

Donor and recipient class I and II HLA typing was tested by molecular methodology. Recipient DNA was purified from whole blood with the QIAamp DNA Blood Mini Kit (QIAGEN Inc, Valencia, Calif). Donor DNA was purified from bone marrow or acid-citrate-dextrose-stored blood. HLA A, B, and DR antigen typings were performed with the low-resolution Micro SSPTM DNA typing kit (One Lambda Inc, Canoga Park, Calif). DNA fragments were separated by agarose gel electrophoresis. HLA antigens were determined through a combination of One Lambda DNA/LMT software analysis and manual interpretation of the electrophoresis results. 
TABLE 1. Patient demographic characteristics

\begin{tabular}{lccr}
\hline Variable & No IVIG & IVIG used & $P$ value \\
\hline No. & 12 & 7 & \\
Age at surgery (d) & $8.2 \pm 4.8$ & $17.1 \pm 14.6$ & .021 \\
Male sex (\%) & $75 \%$ & $71 \%$ & $>.999$ \\
Length (cm) & $50.5 \pm 2.4$ & $51.3 \pm 3.4$ & .608 \\
Weight (kg) & $3.4 \pm 0.4$ & $3.3 \pm 0.5$ & .734 \\
Crossclamp time (min) & $42.6 \pm 27.7$ & $31.1 \pm 17.9$ & .310 \\
Cardiopulmonary bypass & $127.2 \pm 59.7$ & $123.4 \pm 40.0$ & .899 \\
$\quad$ time (min) & & & \\
Total circulatory arrest & $28.0 \pm 10.6$ & $18.4 \pm 10.9$ & .062 \\
$\quad$ time (min) & & & \\
Packed red blood cells & $12.3 \pm 9.6$ & $10.6 \pm 5.0$ & .966 \\
$\quad$ (units) & & & \\
Platelets (units) & $4.8 \pm 7.5$ & $3.7 \pm 4.6$ & $>.999$ \\
Fresh-frozen plasma (units) & $1.2 \pm 1.2$ & $1.6 \pm 1.0$ & .565 \\
Cryoprecipitate (units) & $3.8 \pm 4.3$ & $3.9 \pm 3.2$ & .567 \\
\hline
\end{tabular}

All values are mean \pm SD. IVIG, Intravenous immunoglobulin.

\section{HLA Antibody Analysis}

Screening for anti-HLA antibodies was performed with the Flow PRA Screening Test (One Lambda). Serum samples were analyzed according to manufacturer recommendations. Test control serum samples included a negative control sample from One Lambda (catalog No. FL-NC) and a positive control that was a 1:32 dilution of a local positive pool made from many high-PRA patient sera. A $10-\mu \mathrm{L}$ mixture of class I and class II beads as well as control beads was added to every tube. Patient serum samples $(20 \mu \mathrm{L})$ were added, and the tubes were incubated for 30 minutes. The tubes were washed twice, and $100 \mu \mathrm{L}$ diluted fluorescein isothiocyanate conjugate (antihuman $\mathrm{F}\left[\mathrm{ab}^{\prime}\right] 2$ ) was added. A final wash step was performed, and the beads were analyzed with a FACSCalibur flow cytometer (BD Biosciences, San Jose, Calif). Samples that tested positive for the presence of either class I or class II antibodies were then further tested for specificities with the FlowPRA Specific Antibody Detection Test kit (One Lambda). Specificity analysis was also performed with single-antigen beads if the PRA level was greater than 60\% (catalog Nos. FL2HD and FL1HD; One Lambda). In a few cases, antibody specificity for class II was also determined by enzyme-linked immunosorbent assay. The kit used was Quickscreen Elisa (GTI Inc, Waukesha, Wis).

\section{Data and Statistical Analyses}

All outcomes are expressed as mean $\pm \mathrm{SD}$. Comparisons between continuous data were made with the Mann-Whitney U test, and comparisons between nominal data were made with $\chi^{2}$ or Fisher exact test as appropriate. All statistical analyses were performed with the Statistical Package for Social Sciences (version 13; SPSS Inc, Chicago, Ill).

\section{Results}

Patient demographic characteristics are summarized in Table 1. Except for the control group being somewhat younger $(8.2 \pm 4.8$ vs $17.1 \pm 14.6$ days; $P=.021)$, the two groups were well matched preoperatively. Most of

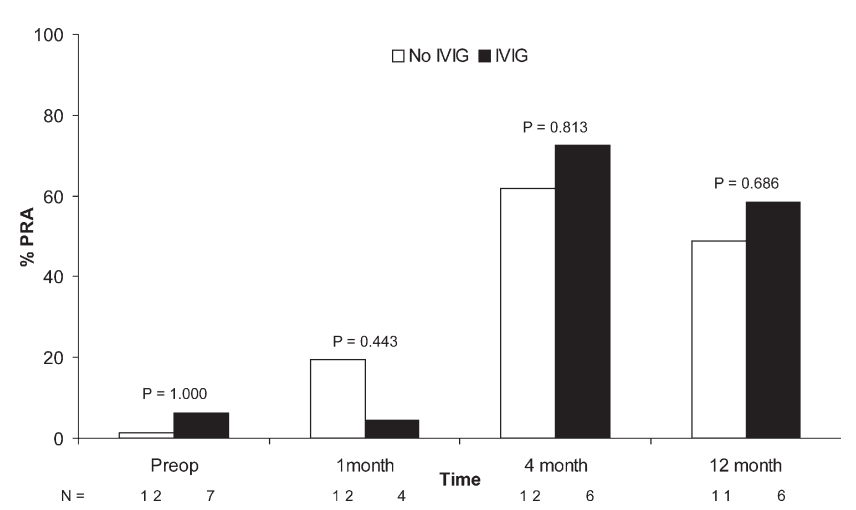

Figure 1. Class I panel-reactive antibody (PRA) levels: preoperative and 1, 4, and 12 months postoperatively. IVIG, Intravenous immunoglobulin.

the discrepancy in age resulted from a single infant in the IVIG group who had surgery delayed until 49 days. Cardiopulmonary bypass times were similar for the two groups (127.2 \pm 59.7 vs $123.4 \pm 40.0$ minutes, $P=.899$ ), but the IVIG group required a marginally shorter circulatory arrest time $(28.0 \pm 10.6$ vs $18.4 \pm 10.9$ minutes, $P=.062)$. Both groups required similar amounts of blood products perioperatively, including packed red blood cells (12.3 \pm 9.6 vs $10.6 \pm 5.0$ units, $P=.966)$, platelets $(4.8 \pm 7.5$ vs $3.7 \pm$ 4.6 units, $P>.999)$, fresh-frozen plasma (1.2 $\pm 1.2 \mathrm{vs}$ $1.6 \pm 1.0$ units, $P=.565)$, and cryoprecipitate $(3.8 \pm 4.3$ vs $3.9 \pm 3.2$ units; $P=.567)$.

The preoperative dose of IVIG was consistently given at $3.0 \pm 2.4$ days before surgery, the second dose at $22.4 \pm 2.8$ days after surgery, and the third dose during hospitalization for the bidirectional cavopulmonary anastomosis procedure (141.3 \pm 28.3 days after initial surgery). IVIG was administered without adverse events.

Relative to control infants who did not receive IVIG, there were no significant differences in class I or II PRA values for those who did receive IVIG (Figures 1 and 2). Preoperatively (before the initial dose of IVIG), there were minor elevations in both class I and II antibodies, most likely reflecting maternally transmitted (passive) antibodies. One month postoperatively (1 week after the second dose of IVIG), there was evidence of a humoral immune response, with modest elevations in class I $(19.7 \% \pm 30.1 \%$ vs $4.5 \% \pm 9.0 \%, P=.443)$ and class II $(17.1 \% \pm 27.5 \%$ vs $20.0 \% \pm 17.1 \%, P=.400)$ PRA for the control and IVIG groups, respectively. Similarly, no significant differences were noted for the control and IVIG groups at 4 months (class I PRA $61.9 \% \pm 39.9 \%$ vs $72.7 \% \pm 41.1 \%$, $P=.813$, class II PRA $49.3 \% \pm 41.9 \%$ vs $53.8 \% \pm 40.5 \%$, $P=.706$ ) and 12 months (class I PRA $49 \% \pm 42 \%$ vs $58 \% \pm 39 \%, P=.686$, class II PRA $44 \% \pm 36 \%$ vs $49 \% \pm$ $42 \%, P=.651)$. A more detailed review of the individual 


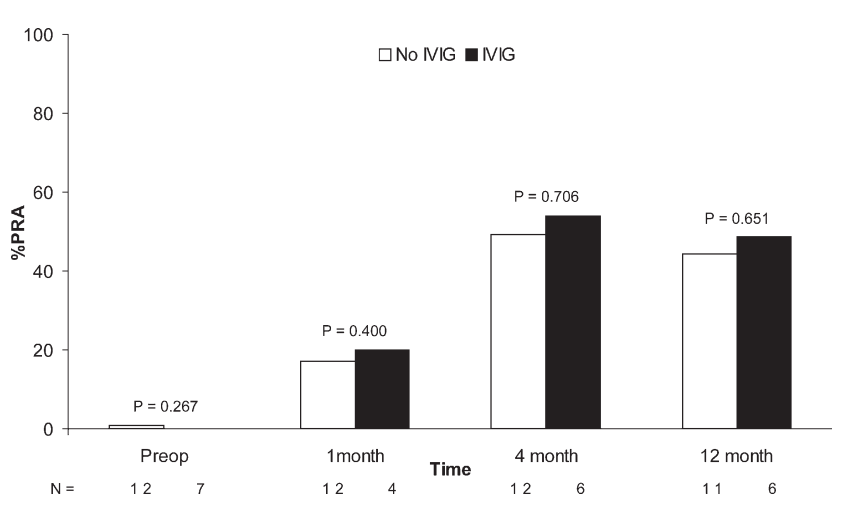

Figure 2. Class II panel-reactive antibody (PRA) levels: preoperative and 1, 4, and 12 months postoperatively. IVIG, Intravenous immunoglobulin.

PRA values at 4 months for recipients of IVIG revealed those with no response to IVIG, with PRA levels approaching $100 \%$, and others with responses, with PRA levels ranging from $0 \%$ to $29 \%$ (Figure 3). Moreover, in a few patients, PRA appeared to decline after 4 months. HLA typing of donor and recipient confirmed that responders were mismatched for both class I and II antigens (Table 2).

\section{Discussion}

The Norwood operation has become the accepted standard of care for neonates with HLHS. Although alternatives have been reported, a cryopreserved allograft pulmonary artery patch has long been the preferred material to reconstruct the diminutive aorta in these infants. Despite previous beliefs that this tissue was immunoprivileged, recent investigations by our group and others have provided evidence that allograft tissues stimulate alloreactive immune responses. Hu$\operatorname{man}^{21}$ and animal ${ }^{22}$ studies have provided evidence for an intense T-lymphocyte response. In addition, others have demonstrated a humoral immune response in recipients of allograft tissue. The published frequency of development of anti-HLA antibodies (PRA) to cardiac valve allografts ranges from $78 \% 8$ to $100 \%,{ }^{9}$ with PRA levels approaching $92 \% .^{7}$ In a prospective cohort study at our institution that compared PRA in infants receiving allograft tissue during the Norwood procedure with that in infants undergoing an arterial switch procedure and not receiving allograft tissue, we clearly demonstrated that children who received allograft tissue had PRA develop approaching $100 \% .{ }^{10}$ Moreover, a substantial proportion of the antibodies were donor specific.

Although the results of the Norwood operation for HLHS are steadily improving, ${ }^{11}$ it is possible that many of these children will eventually require cardiac transplantation. There is concern regarding the impact the previously described sensitization will have on successful transplan-

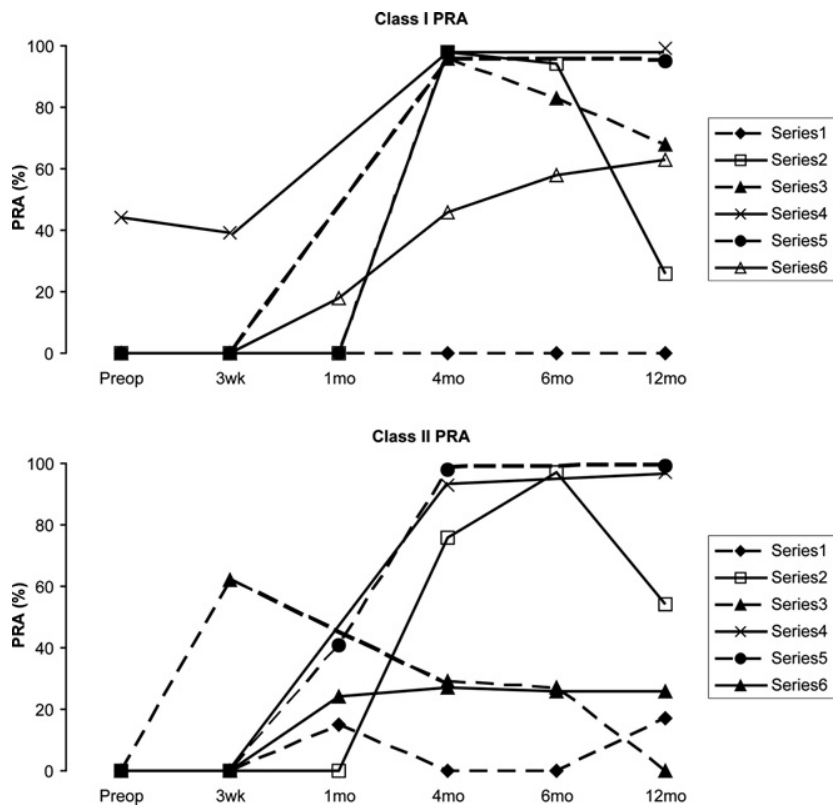

Figure 3. Line plot of panel-reactive antibody (PRA) in infants receiving intravenous immunoglobulin.

tation. It has been documented that the presence of antibodies in the serum of the allograft recipient significantly increases the risk of early allograft failure and poorer patient survival as a result of humoral rejection. ${ }^{1-5}$ Notable is a review by the United Network of Organ Sharing Registry of 14,535 heart transplants performed between 1987 and 1996; it demonstrated that an elevated PRA at transplantation significantly increased the relative risk of graft failure $(P=$ $.0001) .{ }^{4}$ Moreover, a PRA value greater than $60 \%$ was found to be associated with a 2.242 relative risk of graft failure. Similar findings have recently been reported in pediatric heart transplantation. ${ }^{5}$ Consequently, the presence of anti-HLA antibodies limits the ability to find a T-cell crossmatch-negative donor. Waiting times for a suitable allograft are thus considerably longer, and the mortality whilst waiting for a donor is high.

Despite extensive investigation, suitable alternatives to allograft tissue have yet to be identified. Glutaraldehydetreated xenograft tissue tends to undergo rapid calcification and fail even more rapidly than allograft tissue, especially in children. Moreover, no material comes close to the handling properties of allograft tissue, for instance when attempting to reconstruct the aortic arch of a newborn infant. This latter concern is particularly true of synthetic material (eg, polytetrafluoroethylene and Dacron polyester fabric). Thus allograft tissue continues to play an essential role in congenital cardiac surgery. Numerous potential methods exist or are being investigated to reduce the immunogenicity of allograft tissues. Tissue matching (donor-recipient HLA match- 
TABLE 2. Donor-recipient HLA mismatch

\begin{tabular}{|c|c|c|c|c|c|c|}
\hline \multirow[b]{2}{*}{ Case } & \multicolumn{2}{|c|}{ Antigen mismatches* } & \multicolumn{2}{|c|}{ PRA at 4 mo } & \multirow[b]{2}{*}{ Antibody specificities } & \multirow[b]{2}{*}{ Donor-specific antibodies } \\
\hline & Class I & Class II & Class I (\%) & Class II (\%) & & \\
\hline 1 & A1 A24 B8 & DR17 DR15 DR52 & 0 & 0 & NA & NA \\
\hline 2 & A3 B7 B62 & $\begin{array}{l}\text { DR11 DR16 DR51 } \\
\text { DR52 }\end{array}$ & 98 & 76 & $\begin{array}{l}\text { A2 A3 A30 A68 A11 A34 A24 A32 A33 } \\
\text { A31 A23 A13 B35 B62 B45 B60 B44 } \\
\text { B49 B57 B7 B8 B55 B65 DR11DR13 } \\
\text { DR14 DR15 DR16 DR17 DR18 DR52 } \\
\text { DR4 DR5 DR6 DR8 DR9 }\end{array}$ & A3 B7 B62 DR16 DR11 DR52 \\
\hline 3 & $\begin{array}{l}\text { A1 A30 } \\
\text { B18 B63 }\end{array}$ & DR1 DR13 & 96 & 29 & $\begin{array}{c}\text { A1 A3 A29 A30 A26 A11 A32 A31 B18 } \\
\text { B62 B57 B52 B8 DR1 DR103 DR16 }\end{array}$ & A1 A30 B18 DR1 \\
\hline 4 & NA & NA & 98 & 93 & $\begin{array}{l}\text { A } 23 \text { A24 A29 B49 B13 B45 B60 B44 } \\
\text { B57 B7 B8 B55 DR4 DR7 DR13 }\end{array}$ & NA \\
\hline 5 & $\begin{array}{c}\text { A2 B44 } \\
\text { B62 }\end{array}$ & DR4 & 98 & 98 & $\begin{array}{l}\text { A1A2 A68 A25 A26 A34 A32 A23 A24 } \\
\text { A29 A11 B } 49 \text { B51 B52 B62 B35 } \\
\text { B57 B44 B45 B65 }\end{array}$ & $\mathrm{A} 2, \mathrm{~B} 44, \mathrm{~B} 62$ \\
\hline 6 & NA & NA & 46 & 27 & A25 A26 A66 DR1 DR10 & NA \\
\hline $7 \dagger$ & A32 B27 & DR17 DR103 & NA & NA & NA & NA \\
\hline
\end{tabular}

PRA, Panel-reactive antibody; NA, not applicable (donor or recipient typing was not performed). *Antigen mismatches represent donor antigens at which recipient was not matched. TWithdrew from study before 4 months.

ing) would be a complex and expensive process. Decellularization techniques are currently being explored in a number of laboratories, including our own ${ }^{12}$; however, their use requires extensive additional investigation.

Altering the host with typical immunosuppressive agents (eg, cyclosporine [INN ciclosporin], mycophenolate mofetil) is effective but is limited by these agents' well-documented short- and long-term toxicities. ${ }^{14} \mathrm{~A}$ recent study by Shaddy and associates ${ }^{13}$ demonstrated that mycophenolate mofetil $\left(600 \mathrm{mg} / \mathrm{m}^{2}\right.$ per dose) twice daily for 3 months substantially reduces anti-class I (but not anti-class II) antibodies. One patient withdrew after 2 weeks because of a sinus infection that was successfully treated with oral antibiotics, and 3 patients had a transient adverse effect of postoperative vomiting. Of note, this study used leukocyte-depleted blood products, (both filtered and irradiated products) which may have impacted the degree of antibody response. Blood in our study was not routinely irradiated. Long-term use of these agents in children is difficult to justify, despite efficacy.

IVIG is an alternative immunomodulatory agent demonstrated to be safe. Experience with kidney and cardiac transplantation has demonstrated that this agent can produce clinically significant and sustained reductions in anti-HLA antibody titers in individuals who have been previously sensitized, in turn allowing successful transplantation. ${ }^{15-19}$ A recent article by Glotz and colleagues ${ }^{18}$ reported the successful desensitization in 13 of 15 patients (87\%) in a pilot trial with 3 monthly courses of $2 \mathrm{~g} / \mathrm{kg}$ body weight IVIG. These 13 patients underwent immediate kidney transplantation, with loss of only 1 of the kidneys to rejection. In addition, the National Institutes of Health-sponsored IG02 trial randomly assigned 101 adult patients with end-stage renal disease who had a PRA level greater than 50\% to receive either IVIG (2g/kg monthly for 4 months) or placebo. ${ }^{16}$ IVIG therapy was associated with a modest improvement in transplantation rates $(35 \%$ vs $20 \%, P=.069)$, reduced time to transplantation $(P<.05)$, and decreased mortality ( $8 \%$ vs $16 \%, P=.22)$. The numerous mechanisms by which IVIG is thought to exerts its immunomodulatory effects are beyond the scope of this article and have been summarized in a number of recent reviews. ${ }^{23-26}$

In this study we tested the hypothesis that IVIG could reduce development of sensitization in previously unsensitized individuals. Despite the extensive aforementioned documentation of the effectiveness of IVIG in reducing alloreactive antibody levels, this pilot study did not demonstrate any benefit in giving IVIG before and after exposure to allogeneic material. In this study, there was no difference between PRA values of patients receiving IVIG and those of patients not receiving IVIG. The lack of response to IVIG may be dose related; however, we used a dose $(2 \mathrm{~g} / \mathrm{kg})$ that is standard in most successful desensitization protocols, including the National Institutes of Health IG02 trial. ${ }^{15-18}$ Our findings are consistent with a recent trial of IVIG to prevent sensitization in ventricular assist device recipients. ${ }^{20}$ In that trial, IVIG (10 g/d for 3 days) had no effect on either the mean PRA or the number of individuals becoming sensitized during mechanical support. It is important to note that our study did not use additional desensitization techniques, including plasmapheresis and other immunosuppressive agents as noted in many previous case series. 
The dosing regimen took into consideration the half-life of IVIG ( 3 weeks) and the need to administer the agent under closely monitored conditions in highly volume-sensitive infants. This led to the choice of dosing times: preoperative (before exposure to allograft tissue), 3 weeks (infant still in hospital), and 4 months (infant returns for bidirectional cavopulmonary anastomosis). The Stollery Children's Hospital is a tertiary referral center for pediatric heart surgery and receives patients from an extremely large geographic area (Western Canada); thus having infants return for more frequent dosing would not have been possible and would have limited enrollment. Consequently, the major limitation of this study was the need to administer the IVIG while the patient was in the hospital and the resultant inability to administer IVIG at 2 and 3 months after surgery. This period is the critical window of antibody development, when the child is most likely acquiring memory B cells to the allograft tissue. Thus in effect we were only testing the efficacy of the first two doses of IVIG, with the impact of the third dose at 4 months questionable. Regardless, Glotz and colleagues ${ }^{18}$ achieved a 50\% reduction in PRA with 3 monthly courses of $2 \mathrm{~g} / \mathrm{kg}$ IVIG. John and coworkers ${ }^{17}$ reported a mean reduction of $33 \%$ in anti-HLA class I reactivity within 1 week of $2 \mathrm{~g} / \mathrm{kg}$ IVIG. Moreover, Glotz and colleagues ${ }^{18}$ demonstrated that the maximal reduction in alloreactivity occurs within 1 week of IVIG therapy and that sequential doses of IVIG did not have an additive effect on reduction of circulating anti-HLA class I IgG antibodies. Similarly, in the IG02 trial, in which IVIG was administered at $2 \mathrm{~g} / \mathrm{kg}$ monthly for 4 months, most of the reduction in PRA was seen within the first month. ${ }^{16}$ The findings of these studies contrast sharply with ours, in which there was no response to IVIG seen within the first month of therapy.

There are a number of limitations to this study. Small sample size limits statistical calculations. Review of the scatterplots and comparison with control patients who did not receive IVIG, however, demonstrates a lack of response to IVIG. There is also increasing discussion that the PRA may not be the most suitable test to determine sensitivity. ${ }^{27}$ Antibody specificity and titers may be a more sensitive method to determine the degree of sensitization. Alternatively, use of less sensitive methods than flow PRA, such as complement-dependent cytotoxicity and antiglobulin-enhanced complement-dependent cytotoxicity, might have helped determine the impact on antibody titers. If the antibodies we detect after IVIG therapy are low titer, they may be more amenable to subsequent modulation therapies at the time of transplantation. Additionally, longer follow-up may reveal a delayed effect of IVIG after 12 months. Finally, if heart transplantation is required in the future, determination of crossmatch results may be revealing.

In conclusion, this novel study was unable to demonstrate that IVIG prevents sensitization after exposure to allograft tissue in neonates undergoing congenital cardiac surgery. These findings were seen despite studies in adults, which have demonstrated that high-dose $(2 \mathrm{~g} / \mathrm{kg})$ IVIG reduces sensitization. The ultimate test will be long-term follow-up and determination of whether early treatment with IVIG improves future transplantability.

We gratefully acknowledge Lea Legge, Pam Wiebe, Dr Michael Tyrrell, Michelle Loeffler, Patty Knox, Kelly Dealy, and Dr George Sandor for their assistance in following up the study participants at the referring hospitals.

\section{References}

1. Itescu S, Tung TC, Burke EM, Weinberg A, Moazami N, Artrip JH, et al. Preformed IgG antibodies against major histocompatibility complex class II antigens are major risk factors for high-grade cellular rejection in recipients of heart transplantation. Circulation. 1998;98: 786-93.

2. Tambur AR, Bray RA, Takemoto SK, Mancini M, Costanzo MR, Kobashigawa JA, et al. Flow cytometric detection of HLA-specific antibodies as a predictor of heart allograft rejection. Transplantation. 2000;70:1055-9.

3. Kerman RH, Susskind B, Kerman D, Lam M, Gerolami K, Williams $\mathrm{J}$, et al. Comparison of PRA-STAT, sHLA-EIA, and anti-human globulin-panel reactive antibody to identify alloreactivity in pretransplantation sera of heart transplant recipients: correlation to rejection and posttransplantation coronary artery disease. J Heart Lung Transplant. 1998;17:789-94.

4. Thompson JS, Thacker LR 2nd, Takemoto S. The influence of conventional and cross-reactive group HLA matching on cardiac transplant outcome: an analysis from the United Network of Organ Sharing Scientific Registry. Transplantation. 2000;69:2178-86.

5. Jacobs JP, Quintessenza JA, Boucek RJ, Morell VO, Botero LM, Badhwar V, et al. Pediatric cardiac transplantation in children with high panel reactive antibody. Ann Thorac Surg. 2004;78:1703-9.

6. Shaddy RE, Fuller TC. The sensitized pediatric heart transplant candidate: causes, consequences, and treatment options. Pediatr Transplant. 2005;9:208-14.

7. Hawkins JA, Breinholt JP, Lambert LM, Fuller TC, Profaizer T, McGough EC, et al. Class I and class II anti-HLA antibodies after implantation of cryopreserved allograft material in pediatric patients. J Thorac Cardiovasc Surg. 2000;119:324-30.

8. Hoekstra FM, Witvliet M, Knoop CY, Wassenaar C, Bogers AJ, Weimar W, et al. Immunogenic human leukocyte antigen class II antigens on human cardiac valves induce specific alloantibodies. Ann Thorac Surg. 1998;66:2022-6.

9. Smith JD, Ogino H, Hunt D, Laylor RM, Rose ML, Yacoub MH. Humoral immune response to human aortic valve homografts. Ann Thorac Surg. 1995;60(2 Suppl):S127-30.

10. Meyer SR, Campbell PM, Rutledge JM, Halpin AM, Hawkins LE, Lakey JR, et al. Use of an allograft patch in repair of hypoplastic left heart syndrome may complicate future transplantation. Eur J Cardiothorac Surg. 2005;27:554-60.

11. Azakie T, Merklinger SL, McCrindle BW, Van Arsdell GS, Lee KJ, Benson LN, et al. Evolving strategies and improving outcomes of the modified Norwood procedure: a 10-year single-institution experience. Ann Thorac Surg. 2001;72:1349-53.

12. Meyer SR, Nagendran J, Desai LS, Rayat GR, Churchill TA, Anderson CC, et al. Decellularization reduces the immune response to aortic valve allografts in the rat. J Thorac Cardiovasc Surg. 2005; $130: 469-76$.

13. Shaddy RE, Fuller TC, Anderson JB, Lambert LM, Brinkman MK, Profaizer T, et al. Mycophenolic mofetil reduces the HLA antibody response of children to valved allograft implantation. Ann Thorac Surg. 2004;77:1734-9.

14. Lindenfeld J, Miller GG, Shakar SF, Zolty R, Lowes BD, Wolfel EE, et al. Drug therapy in the heart transplant recipient: part II: immunosuppressive drugs. Circulation. 2004;110:3858-65. 
15. Jordan SC, Vo A, Bunnapradist S, Toyoda M, Peng A, Puliyanda D, et al. Intravenous immune globulin treatment inhibits crossmatch positivity and allows for successful transplantation of incompatible organs in living-donor and cadaver recipients. Transplantation. 2003; 76:631-6.

16. Jordan SC, Tyan D, Stablein D, McIntosh M, Rose S, Vo A, et al. Evaluation of intravenous immunoglobulin as an agent to lower allosensitization and improve transplantation in highly sensitized adult patients with end-stage renal disease: report of the NIH IG02 trial. J Am Soc Nephrol. 2004;15:3256-62.

17. John R, Lietz K, Burke E, Ankersmit J, Mancini D, Suciu-Foca N, et al. Intravenous immunoglobulin reduces anti-HLA alloreactivity and shortens waiting time to cardiac transplantation in highly sensitized left ventricular assist device recipients. Circulation. 1999;100(19 Suppl):II229-35.

18. Glotz D, Antoine C, Julia P, Suberbielle-Boissel C, Boudjeltia S, Fraoui R, et al. Desensitization and subsequent kidney transplantation of patients using intravenous immunoglobulins (IVIg). Am J Transplant. 2002;2:758-60.

19. Pisani BA, Mullen GM, Malinowska K, Lawless CE, Mendez J, Silver MA, et al. Plasmapheresis with intravenous immunoglobulin $G$ is effective in patients with elevated panel reactive antibody prior to cardiac transplantation. J Heart Lung Transplant. 1999;18:701-6.

20. Drakos SG, Kfoury AG, Long JW, Stringham JC, Fuller TC, Nelson $\mathrm{KE}$, et al. Low-dose prophylactic intravenous immunoglobulin does not prevent HLA sensitization in left ventricular assist device recipients. Ann Thorac Surg. 2006;82:889-93.

21. Oei FB, Welters MJ, Knoop CJ, Vaessen LM, Stegmann AP, Weimar $\mathrm{W}$, et al. Circulating donor-specific cytotoxic T lymphocytes with high avidity for donor human leukocyte antigens in pediatric and adult cardiac allograft valved conduit recipients. Eur J Cardiothorac Surg. 2000;18:466-72.

22. Legare JF, Lee TD, Creaser K, Ross DB. T lymphocytes mediate leaflet destruction and allograft aortic valve failure in rats. Ann Thorac Surg. 2000;70:1238-45.

23. Jordan S, Cunningham-Rundles C, McEwan R. Utility of intravenous immune globulin in kidney transplantation: efficacy, safety, and cost implications. Am J Transplant. 2003;3:653-64.

24. Gelfand EW. Antibody-directed therapy: past, present, and future. J Allergy Clin Immunol. 2001;108(4 Suppl):S111-6.

25. Kazatchkine MD, Kaveri SV. Immunomodulation of autoimmune and inflammatory diseases with intravenous immune globulin. $\mathrm{N} \mathrm{Engl}$ J Med. 2001;345:747-55.

26. Sewell WA, Jolles S. Immunomodulatory action of intravenous immunoglobulin. Immunology. 2002;107:387-93.

27. Montgomery RA, Hardy MA, Jordan SC, Racusen LC, Ratner LE, Tyan DB, et al. Consensus opinion from the antibody working group on the diagnosis, reporting, and risk assessment for antibody-mediated rejection and desensitization protocols. Transplantation. 2004;78: 181-5.

\section{Online-www.aats.org}

Now you can get The Journal of Thoracic and Cardiovascular Surgery online. The Journal online brings you faster delivery time, easy searching of current and back issues, links to PubMed, AATS, WTSA, and other important sites, and more. Visit the Journal online today.

\section{Receive tables of contents by e-mail}

To receive the tables of contents by e-mail, sign up through our Web site at http://journals. elsevierhealth.com/periodicals/ymtc

Choose E-mail Notification

Simply type your e-mail address in the box and click the Subscribe button. You will receive an e-mail to confirm that you have been added to the mailing list.

Note that TOC e-mails will be sent out when a new issue is posted to the Web site. 